\title{
A TRAJETÓRIA DO MOVIMENTO SOCIAL PELO RECONHECIMENTO DA CIDADANIA LGBT ${ }^{1}$
}

\author{
José Cleudo Gomes* \\ Maria de Nazaré Tavares Zenaide**
}

\begin{abstract}
Resumo: Este trabalho retoma um dos temas tratados em pesquisa de mestrado, que buscou analisar as ações implementadas pelo então Programa Brasil sem Homofobia do Governo Federal, a partir da sua transversalidade com as políticas públicas e das interfaces com o movimento de Lésbicas, Gays, Bissexuais, Travestis e Transexuais (LGBT) em nível local. Dessa maneira, o objetivo deste artigo é refletir a noção de cidadania, a partir da história do movimento social LGBT, recorrendo aos seguintes referenciais teóricos: Marshall (1976); Dagnino (1994); Benevides (1996); Cortina (2005); Gohn (1997). Trata-se, portanto, de uma pesquisa bibliográfica, na qual foi realizada uma revisão de literatura de cunho exploratório e com abordagem qualitativa, em que evidenciamos a trajetória do Movimento LGBT, em nível internacional, nacional e local, enfatizando o seu surgimento e a sua luta pelo reconhecimento da cidadania de LGBT, a partir de obras científicas e escritos da própria militância, tais como Green (2003); Facchini (2005); MacRae (2011); Reis (2012); Vieira, L. (2015). Como resultados, apontamos as conquistas do movimento LGBT no contex to democrático a partir das dimensões política, civil, econômica e social como parte da trajetória e reconhecimento da luta social e cidadania LGBT.
\end{abstract}

Palavras-chave: Movimento Social. Cidadania. História do Movimento LGBT.

\section{Introdução}

Neste artigo, evidenciamos a trajetória do Movimento de Lésbicas, Gays, Bissexuais, Travestis e Transexuais (LGBT), em nível internacional, nacional e local, enfatizando o seu surgimento e a sua luta pelo reconhecimento da cidadania LGBT, a partir de obras científicas e de escritos da própria militância, tais como Green (2003); Facchini (2005); MacRae (2011); Reis (2012); Vieira, L. (2015). Para isso, buscamos entrelaçar a noção de cidadania, a partir da história do movimento social, recorrendo aos seguintes referenciais teóricos: Marshall (1976); Dagnino (1994); Benevides (1996); Cortina (2005) e Gohn (1997).

\footnotetext{
${ }^{1} \mathrm{O}$ presente trabalho foi realizado com apoio da Coordenação de Aperfeiçoamento de Pessoal de Nível Superior - Brasil (CAPES) - Código de Financiamento 001.

*Doutorando em Educação no Programa de Pós-Graduação em Educação da Universidade Federal da Paraíba (UFPB). Possui Mestrado em Educação pela mesma instituição.

** Doutora em Educação pelo Programa de Pós-Graduação em Educação (PPGE) da Universidade Federal da Paraíba (UFPB). Professora associada do Departamento de Serviço Social da UFPB. Atua como docente no PPGE e no Programa de Pós-Graduação em Direitos Humanos, Cidadania e Políticas Públicas da UFPB.
} 
Este texto apresenta um recorte de uma pesquisa de mestrado em que os autores (respectivamente: orientando e orientadora) buscaram analisar as ações implementadas pelo então Programa Brasil sem Homofobia, ${ }^{2}$ a partir da sua transversalidade com as políticas públicas e das interfaces com o movimento LGBT em nível local (GOMES, 2016).

A investigação fundamentou-se na abordagem qualitativa, uma vez que recorremos aos procedimentos da pesquisa bibliográfica cuja finalidade, de acordo com Marconi e Lakatos (2011, p. 43), "[...] é colocar o pesquisador em contato direto com tudo o que foi escrito, dito ou filmado sobre determinado assunto", tipo livros e publicações acadêmicas. Desse modo, identificamos as pesquisas que foram desenvolvidas acerca da temática, utilizando como ferramenta de busca o Banco de Teses e Dissertações da CAPES. Nesse processo, foram identificados artigos científicos, dissertações, teses e livros que resultam de pesquisas sobre a história e a memória do movimento LGBT, dialogando com a categoria cidadania, previamente definida no estudo maior que resultou este artigo.

A finalidade do artigo não é realizar um ensaio do conceito de cidadania, nem tão pouco se tem a intenção pretensiosa de esgotar seus sentidos contemporâneos, já que sua origem tem raízes gregas e romanas, "há mais ou menos vinte e quatro séculos", e, ao longo desses anos, há um "conjunto de conotações difíceis de sintetizar em uma definição" (CORTINA, 2005, p. 51). Com efeito,

[...] entende-se que a realidade da cidadania, o fato de se saber e de se sentir cidadão de uma comunidade, pode motivar os indivíduos a trabalhar por ela. Com isso, nesse conceito se encontrariam os lados a que nos referimos: o lado 'racional', o de uma sociedade que deve ser justa para seus membros percebam sua legitimidade, e o lado 'obscuro', representando por esses laços de pertença que não escolhemos, mas já fazem parte de nossa identidade. Ante os desafios com os quais qualquer comunidade se depara, é possível apelar então a razão e ao sentimento de seus membros, já que são cidadãos dessa comunidade, algo seu [...]. (CORTINA, 2005, p. 27, grifos da autora).

A vivência dos movimentos sociais está vinculada à noção de cidadania, na medida em que o reconhecimento do direito a ter direitos cria possibilidades e potencialidades políticas, conforme enaltece a professora Evelina Dagnino (1994, p. 104):

\footnotetext{
2 O Brasil sem Homofobia (BSH), Programa de Combate à Violência e à Discriminação contra LGBT e Promoção da Cidadania Homossexual, foi uma ação pioneira do Governo Lula (2003-2011) voltada à população LGBT, que desencadeou a elaboração e implementação de políticas públicas para o segmento em diversos Ministérios e contou com a participação do movimento social em sua elaboração. Esse programa foi extinto, em 2009, com a publicação do Plano Nacional de Promoção da Cidadania e Direitos Humanos de LGBT, resultante da I Conferência Nacional GLBT, e reformulado em 2011.

3 Os conceitos de cidadão e de cidadania são buscados nos tempos remotos e clássicos de Atenas, dos séculos $\mathrm{V}$ e IV a.C., e de Roma, do século III a.C. até o século I da Era Cristã. (CORTINA, 2005).
}

\# Tear: Revista de Educação Ciência e Tecnologia, Canoas, v.8, n.1, 2019. 
Em primeiro lugar, o fato de que ela deriva e, portanto, está intrinsecamente ligada à experiência concreta dos movimentos sociais, tanto os de tipo urbano - e aqui é interessante anotar como cidadania se entrelaça com o acesso à cidade - quanto os movimentos de mulheres, negros, homossexuais, ecológicos etc. $\mathrm{Na}$ organização desses movimentos sociais, a luta por direitos - tanto o direito à igualdade como o direito à diferença - constituiu a base fundamental para a emergência de uma nova noção de cidadania. (grifos da autora).

Gohn (1997), ao abordar a Teoria dos Novos Movimentos Sociais, chama atenção, na atualidade, para os novos atores em cena, envolvendo os diversos grupos identitários - pessoas com deficiência, mulheres, negros (as), LGBTs, entre outros - que, em tempo de globalização, tencionam a esfera pública e as ruas com as lutas por reconhecimento social e por cidadania.

Entretanto, não queremos afirmar, com isso, que o exercício pleno da cidadania em suas dimensões civis, sociais e políticas possam ser exercidos apenas dentro do movimento social, embora este seja o ator político que incorpora as identidades LGBTs e o coletivo. O movimento LGBT, então, se torna um espaço social de fortalecimento do sentimento de pertença a uma determinada comunidade de interesses, assim como é também um espaço de aprendizagem social onde o segmento fortalece os meios de participação social e política. Segundo Vitória Benevides (1997, p.12), a educação para a cidadania democrática exige a experiência enquanto sujeitos políticos, na medida em que:

O primeiro ponto consiste na necessidade da tomada de consciência dos direitos e dos deveres do cidadão. O artigo 13 do Pacto Internacional das Nações Unidas de 1966 reconhece não apenas o direito de todas as pessoas à educação, mas que esta deve visar o pleno desenvolvimento da personalidade humana, na sua dignidade, deve fortalecer o respeito pelos Direitos Humanos e as liberdades fundamentais, deve capacitar todas as pessoas a participar efetivamente de uma sociedade livre. Essa participação significa organização e participação pela base, rompendo a verticalidade absoluta dos poderes autoritários. Significa, também, o reconhecimento (e a constante reivindicação) de que os cidadãos ativos são mais do que titulares de direitos, são criadores de direitos e novos espaços para a expressão de tais direitos. (grifos da autora).

Marshall (1976) $)^{4}$ concebe três elementos de direitos da cidadania que se interligam direitos civis, direitos políticos e direitos sociais. Já Cortina (2005) amplia a discussão sobre cidadania, abordando que é preciso pensar sobre a cidadania como uma construção social que é atravessada pelas dimensões histórica, social, civil, econômica e intercultural. Desse modo, a autora afirma que o conceito de cidadania plena envolve aspectos relacionados à identidade, à liberdade e à igualdade, uma vez que insere "um status legal (um conjunto de direitos), um

\footnotetext{
${ }^{4}$ Considerado um dos primeiros teóricos da cidadania. Ver: MARSHALL, Thomas Humphrey. Cidadania, Classe Social e Status. Rio de Janeiro: Zahar Editores, 1976.
}

\# Tear: Revista de Educação Ciência e Tecnologia, Canoas, v.8, n.1, 2019. 
status moral (um conjunto de responsabilidades) e também uma identidade, pela qual uma pessoa sabe e sente que pertence a uma sociedade.” (CORTINA, 2005, p. 139).

Para Cortina (2005, p. 156), “a identidade não nos é dada, mas a negociamos - daí a importância das lutas sociais empreendidas para obter o reconhecimento dos outros significativos". A pesquisadora ressalta a dimensão da cultura, para ressaltar como os territórios estão repletos de diferentes tipos de culturas e de modo de agir que demandam a construção de múltiplas identidades e formas de pertencimento social.

Os membros do segmento LGBT se organizam alicerçados na necessidade individual e coletiva de autoproteção, acessadas a partir de um sentimento de pertencimento identitário que os torna um bloco, um grupo com capacidade de se mover na busca de reconhecimento da garantia de acessar os direitos de modo geral e os canais de participação social pela conquista legal, como do reconhecimento social do direito a ter direitos, como por exemplo, o acesso aos serviços sociais e às políticas públicas.

Dessa forma, percebe-se que, a partir das estratégias de lutas pela cidadania como segmentos LGBT, a força do grupo social cria possibilidades de organização coletiva capazes de potencializar a elaboração e a efetivação de políticas públicas para população LGBT, seja de acesso às liberdades fundamentais, de promoção da igualdade ou de respeito à diversidade.

Como esclarece Gohn (2011, p. 335), os movimentos sociais se expressam pela cidadania coletiva em ações concretas em que "adotam diferentes estratégias que variam da simples denúncia, passando pela pressão direta (mobilizações, marchas, concentrações, passeatas, distúrbios à ordem constituída, atos de desobediência civil, negociações etc.) até as pressões indiretas".

\section{A trilha do movimento homossexual na luta por direitos: aspectos históricos e políticos}

O ápice do surgimento do movimento de defesa dos direitos dos homossexuais se dá a partir dos Estados Unidos, ao longo do século XX, no meio das "diferentes minorias que clamavam por seus direitos" (BERUTTI, 2010, p. 37). Vale salientar que alguns autores como Green (2003); Okita (2007) e MacRae (2011) citam que a luta contra a discriminação dos homossexuais surgiu na Europa, ainda no século XIX. ${ }^{5}$

\footnotetext{
${ }^{5}$ Nos limites deste artigo não foi possível detalhar esses aspectos históricos, assim optamos em aprofundar o recorte a partir do ressurgimento do movimento norte-americano que influenciou outros países do continente.
}

\# Tear: Revista de Educação Ciência e Tecnologia, Canoas, v.8, n.1, 2019. 
Foi nos Estados Unidos que, por volta de 1950, se formou a Mattachine Society, ${ }^{6}$ uma organização política semiclandestina de gays e lésbicas que visava à integração dos homossexuais na sociedade, pois considerava-se que era dado um status socialmente marginal ao segmento. ${ }^{7}$

De acordo com Green (2003, p. 24),

[...] grupos relativamente pequenos e isolados, ofereceram as bases para a organização de outros esforços contra a discriminação e homofobia numa época em que os direitos civis e as atividades anti-guerra inspiraram uma segunda onda de feminismo e novas organizações pelos direitos dos gays e lésbicas no final da década de 1960.

Provavelmente, o movimento de maio de 1968 que aconteceu na França, inspirou a militância norte-americana que, semelhantemente à juventude europeia, questionava os valores morais da época. A revolta estudantil de 1968 desencadeou o aparecimento do movimento de contracultura, com o movimento hippie, com a luta das mulheres em busca de sua afirmação na sociedade, como também dos negros que protestavam por direitos civis, "além das revoltas estudantis nas universidades, a desobediência civil dos jovens contra a guerra do Vietnã." (BERUTTI, 2010, p. 37).

A década de 1960 foi essencial para a expansão da militância gay nos Estados Unidos e, por consequência, influenciou outros países da América e da Europa, porque foi exatamente nos Estados Unidos que aconteceu o surgimento do Movimento Homossexual Moderno.

No dia 28 de junho de 1969, aconteceu a Revolta de Stonewall, um episódio que marcou para sempre a militância LGBT de todo o mundo. O fato ocorreu na cidade de Nova York, no bar The Stonewall Inn, localizado na Christopher Street, número 53, um espaço frequentado por gays, lésbicas e travestis, em que cotidianamente aconteciam batidas da polícia, e seus frequentadores eram forçados a sair e, na maioria das vezes, sofriam repressão policial, porém, nesse dia, "ao invés de fugir, eles, liderados por travestis, trancaram os policiais no bar, incendiaram e atiraram pedras e garrafas quando os policiais tentavam sair" (OKITA, 2007, p. 73). De acordo com MacRae (2011, p. 26), "a luta foi bastante violenta e os homossexuais, além de evidenciar a fúria inusitada contra seus tradicionais repressores, também gritaram

\footnotetext{
${ }^{6}$ Fundada por membros do Partido Comunista que adotavam uma linha moderada e cautelar (GREEN, 2003; MACRAE, 2011).

7 Nesse período já havia divergências entre os gays e as lésbicas, assim ocorreram dissidências no Mattachine Society e foi formado em 1955, na cidade de São Francisco, as Daughters of Bilitis, grupo formado apenas por lésbicas. (SIMÕES; FACCHINI, 2009).
}

\# Tear: Revista de Educação Ciência e Tecnologia, Canoas, v.8, n.1, 2019. 
palavras de ordem". Assim, a Revolta de Stonewall durou cerca de três dias, com intenso conforto da polícia contra os homossexuais nas ruas de Nova York.

A pesquisadora Eliane Berutti (2010, p. 40) afirma que

[...] The Stonewall Inn foi palco da pior batida de polícia de sua história e viveu seu momento final. [...] Faz-se desnecessário pontuar por que todos os anos de invisibilidade e opressão finalmente explodiram no confronto com a polícia. Um ano depois, com a intenção de comemorar as revoltas de Stonewall, [aconteceu] a passeata do Orgulho Gay tomou conta das ruas da cidade de Nova York.

Um ano depois, aconteceu uma passeata que reuniu cerca de dez mil homossexuais, para comemorar a Rebelião de Stonewall, e o dia 28 de junho ficou conhecido como Dia do Orgulho Gay. ${ }^{8}$ Desse modo, foi formada a Gay Liberation Front (Frente de Libertação Homossexual) que teve implicações mundiais, pois centenas de organizações de homossexuais começaram a surgir (OKITA, 2007, MACRAE, 2011).

Segundo Okita (2007, p. 74),

\begin{abstract}
Inspirados nas lutas dos negros, mulheres, heróis vietnamitas, o movimento tomou uma orientação altamente política. Nos anos seguintes, o movimento forçou a várias mudanças na sociedade norte-americana. Forçaram a Associação Americana de Psiquiatria ${ }^{9}$ a repensar sua classificação tradicional de homossexual como doente e ganhou cobertura ampla nas suas reivindicações básicas: fim da discriminação no emprego, na habitação, fim dos ataques policiais contra a comunidade homossexual, pelos direitos dos professores etc. (OKITA, 2007, p. 74).
\end{abstract}

Com isso, as ações da Frente de Libertação Homossexual se espalharam por outros estados americanos, e, assim, surgiriam lideranças do movimento homossexual, como Harvey Milk, em São Francisco, um dos poucos ícones do movimento que são evidenciados na história da luta em defesa dos direitos dos homossexuais. Diferentemente dos demais movimentos sociais, os líderes do movimento homossexual foram invisibilizados pela história. Harvey Milk foi um militante assumidamente gay que se elegeu supervisor em São Francisco, o que equivale ao cargo de vereador no Brasil, sendo o primeiro homossexual a ser eleito para um cargo público nos Estados Unidos, porém, só foi eleito depois de inúmeras derrotas, conseguindo a vitória somente na terceira tentativa, mas, após a conquista, foi assassinado à queima roupa por outro

\footnotetext{
${ }^{8}$ Atualmente, o dia 28 de junho é comemorado como o Dia do Orgulho LGBT, tendo sido, inclusive, incorporado no calendário de alguns estados e municípios brasileiros.

9 Desde 1973, a Associação Americana de Psiquiatria retirou a homossexualidade da lista de distúrbios mentais.
}

\# Tear: Revista de Educação Ciência e Tecnologia, Canoas, v.8, n.1, 2019. 
supervisor que não admitia a ascensão dos direitos dos homossexuais. A vida e o ativismo de Milk se tornaram uma das referências do movimento homossexual no mundo. ${ }^{10}$

James Green (2003), historiador e pesquisador dos movimentos sociais afirma que a batalha dos gays e lésbicas contra a polícia nas ruas de Nova York influenciaram o surgimento de organizações gays em outros países da América Latina. Na Argentina, meses depois do ato de Stonewall, foi fundado o El Grupo Nuestro Mundo, um grupo formado por dez homossexuais que, juntamente com outros pequenos grupos, formou a Frente de Libertação Homossexual da Argentina (FLH), em 1971. Green descreve ainda que,

\begin{abstract}
No início da década de 1970, grupos semelhantes de gays e lésbicas apareceram no México e em Porto Rico, num contexto de ascensão política mundial. [...] As culturas homossexuais urbanas da Cidade do México, de San Juan e de Buenos Aires revelaram-se solos férteis para desenvolvimentos dos movimentos dos gays e lésbicas dentro dessa avalanche de revoltas políticas do final da década de 1960 e início de 1970. Assim, não surpreenderia que um desses grupos que se formaram no México, em 1978, a Frente Homossexual de Acción Revolucionaria, adotasse a linguagem e o simbolismo da esquerda. Da mesma forma, na Argentina, ativistas formaram, em 1971, a Frente de Liberación Homossexual de La Argentina (FLH) com a coalizão de quatro grupos diferentes. (GREEN, 2003, p. 27).
\end{abstract}

Vale salientar que na maioria dessas organizações havia uma forte influência política, já que agregava homossexuais que tinham sido expulsos do Partido Comunista. Entretanto, alguns políticos de esquerda contribuíram com a luta dos direitos dos homossexuais, tanto no México como na Argentina. Mas, nem em todos os países da América, a cidadania dos homossexuais foi respeitada.

Em Cuba e Nicarágua, autoafirmação e organização entre os gays, lésbicas e outros transgressores sexuais, foram compulsoriamente suprimidos antes de alcançar qualquer grau de aceitação. A profunda homofobia e heterossexismo da sociedade cubana, então mobilizada pela revolução, permitiu posturas e práticas que, só muito lentamente, foram eliminadas, à medida que as minorias sexuais reivindicavam visibilidade. (GREEN, 2003, p. 18).

Apesar de Cuba ser a referência socialista na América Central, a Revolução Cubana sofreu forte influência stalinista que "considera a homossexualidade como decadência burguesa" (OKITA, 2007, p. 70), e, dessa forma, o país passou muito anos reprimindo a homossexualidade com trabalhos forçados na produção da cana de açúcar, sendo alvo de crítica da militância LGBT até os dias atuais.

${ }^{10}$ Em 2008, a história de Harvey Milk se tornou conhecida a partir do lançamento do filme Milk: $a$ voz da igualdade, estrelado por Sean Penn, com direção de Gus Van Sant.

\# Tear: Revista de Educação Ciência e Tecnologia, Canoas, v.8, n.1, 2019. 
Green (2003) afirma que a forte repressão aos homossexuais aconteceu em diversos países da América Latina em períodos de ditadura militar, sobretudo em Porto Rico, México, Argentina e Brasil. ${ }^{11}$

Assim, entendemos que o Movimento LGBT atual é um dos sobreviventes da repressão militar que aconteceu em diversos países do América Latina e teve o seu surgimento marcado pela Revolta de Stonewall, que influenciou a expansão da luta contra a intolerância em outros países, inclusive no Brasil, como veremos no tópico a seguir.

\section{Para além de Stonewall: o movimento homossexual floresce no Brasil}

O Movimento LGBT, no Brasil, anteriormente, conhecido como Movimento Homossexual Brasileiro (MHB), tem pouco mais de quarenta anos de existência e, ao longo desses anos, sofreu inúmeras mudanças, que vão desde a modificação de sua nomenclatura, passando de MHB para a sigla LGBT, a qual teve constantes alterações até chegar ao formato atual. $^{12}$

Essas mudanças ocorreram para dar visibilidade às mulheres lésbicas e às travestis no Movimento Homossexual Brasileiro. As lésbicas passaram a ter uma maior organização em âmbito nacional só na segunda metade dos anos 1990, e, nesse mesmo período, começaram a surgir as organizações independentes de travestis e transexuais que, ao longo dos anos, foram se inserindo e fortalecendo o segmento, buscando, assim, o reconhecimento de suas identidades junto ao então movimento homossexual, já que os "homens predominaram nas organizações do movimento brasileiro, desde suas primeiras fases.” (SIMÕES; FACCHINI, 2009, p. 15).

No Brasil, após a realização da I Conferência Nacional GLBT, em 2008, “decidiu-se pelo uso da terminologia LGBT para identificar a ação conjunta de lésbicas, gays, bissexuais,

\footnotetext{
${ }^{11}$ O Brasil viveu durante 21 anos sobre a Ditadura Militar, instaurada pelo Golpe Civil Militar que ocorreu em $1^{\circ}$ de abril de 1964 e durou até 15 de março de 1985. Segundo Green (2003, p. 31), "embora os homens e as mulheres homossexuais não fossem alvos diretos da ditadura, o crescente número de policiais militares nas ruas, o uso arbitrário da lei e a generalizada vigilância nas expressões artísticas e literárias criaram um clima que desencorajava a possibilidade de emergência de um movimento por direitos dos gays e lésbicas no início dos anos de 1970".

12 Atualmente, outras letras vêm sendo incorporadas à sigla LGBT, tais como o Q de Queer que engloba as orientações e identidades sem ter a pretensão de especificar apenas uma delas. Já o I de Intersex é um "termo que se refere a uma variedade de condições (genéticas e/ou somáticas) com que uma pessoa nasce, apresentando uma anatomia reprodutiva e sexual que não se ajusta às definições típicas do feminino ou do masculino." (ABGLT, 2010, p. 14). Daí, hoje, temos o uso da sigla LGBTQI+, no espaço acadêmico e nas lutas sociais, já que outros sujeitos identitários buscam visibilidade às distintas pautas de cada um dos grupos e à pluralização do movimento, que ganha novas dimensões e configurações. Contudo, adotamos o uso da sigla LGBT, tendo em vista que, desde 2008, é a utilizada pelo movimento social em âmbito nacional.
}

\# Tear: Revista de Educação Ciência e Tecnologia, Canoas, v.8, n.1, 2019. 
travestis e transexuais" (ABGLT, 2010, p. 15), dessa forma, esta é a sigla que utilizaremos no decorrer deste texto.

Facchini (2005, p. 21) afirma que "a proliferação de siglas e a segmentação de categorias com a finalidade de nomear o sujeito político do movimento foram, no ano de 1999, alvos de tratamento irônico na mídia que acusava as entidades que passaram a utilizar a sigla GLBT de criar uma "sopa de letrinhas", e essa metamorfose desencadeada pelas constantes mudanças das siglas gerou muita confusão na literatura, nos estudos da homocultura, na imprensa e, sobretudo, na população que não conseguia assimilar a sigla e/ou denominação politicamente correta vinculada ao movimento. Entretanto, concordamos com Rossi (2010, p. 71), quando diz que "essa transformação das siglas ao longo da história mostra um pouco da evolução do próprio movimento que, ao longo das décadas, foi incorporando a luta de lésbicas, travestis e recentemente das transexuais". Esse paradoxo existente no Movimento LGBT Brasileiro em torno de sua própria identidade é fruto de como surgiu o próprio movimento em nível internacional, o qual foi cercado de turbulências até chegar ao Brasil.

Peter Fry (2009) cita que a trajetória do Movimento LGBT, no Brasil, pode ser dividida em três fases de intensa busca em torno do reconhecimento pelos seus direitos junto à sociedade, sendo a primeira marcada pelo lançamento do Jornal O Lampião da Esquina e pelo surgimento dos pequenos grupos homossexuais em plena ditadura militar.

De acordo com James Green (2000, p. 395),

[...] Em 1978, um pequeno grupo de intelectuais do Rio de Janeiro e de São Paulo fundou o Lampião da Esquina, um tabloide mensal de ampla circulação dirigido ao público gay. Muitos meses depois, um grupo de homens em São Paulo formou o SOMOS, a primeira organização pelos direitos gays do país.

O início do movimento homossexual, no Brasil, tem forte influência da cultura e do movimento gay norte-americano, no final dos anos 1970. Em pleno processo de abertura política, o ativista João Antonio Mascarenhas, considerado como o pioneiro do ativismo gay brasileiro (HOWES, 2003) trouxe ao Brasil, o jornalista Winston Leyland, editor da Revista norte-americana Gay Sunshine para uma palestra que teve grande repercussão na imprensa local e, posteriormente, para um encontro com jornalistas, escritores e intelectuais brasileiros da época, entre os quais, destacamos: Aguinaldo Silva, João Silvério Trevisan, Peter Fry, entre outros que resolveram criar em 1978, no Rio de Janeiro, o Jornal O Lampião da Esquina, que se tornou o principal veículo de comunicação sobre homossexualidade de 1978 a 1981. 
[O jornal] Lampião se diferenciava também no modo como abordava a homossexualidade. O jornal procurava oferecer um tratamento que combatesse a imagem dos homossexuais como criaturas destroçadas por causa de seu desejo, incapazes de realização pessoal e com tendências a rejeitar a própria sexualidade. Mas não fazia isso de modo a concentrar-se exclusivamente nos homossexuais e, sim, apresentando-os como uma entre as várias minorias oprimidas que tinham direito à voz. O jornal se propunha a "sair do gueto" e ser um veículo pluralista aberto a diferentes pontos de vista sobre diferentes questões minoritárias. (SIMÕES, FACCHINI, 2009, p. 85-86).

A veiculação do Lampião da Esquina ocorreu em plena ditadura e passou a ser alvo dos militares, que o consideravam subversivo por evidenciar os homossexuais. De acordo com Fernanda Vieira (2015), a ditadura no Brasil:

[...] Além da caça a homossexuais e travestis nas ruas, para "limpeza", empreendeuse forte mecanismo de censura contra jornais, revistas, ou quaisquer outros meios que dessem alguma visibilidade a essas pessoas transviadas. Notório foi o caso do jornal "O Lampião da esquina”, destinado ao público homossexual, e que foi combatido amplamente pela censura, porém resistiu. [...] Outro aspecto importante é sabermos que durante este período a homossexualidade (então conhecida como "homossexualismo") era entendida como uma patologia. Muitos gays, lésbicas, travestis e transexuais foram internadas em manicômios [...]. (VIEIRA, F., 2015, online).

Esse clima de tensão e horror só foi amenizado quando a sociedade brasileira se mobilizou contra a ditadura militar, favorecendo o crescimento do movimento pelas "Diretas Já”, em 1984. Nesse período, os movimentos sociais emergiram e contribuíram para o processo de redemocratização do Brasil. Dessa forma, “[...] como o movimento [homossexual] brasileiro florescia sob estas condições de liberdade, surgiram também novos grupos na maioria dos países do continente." (GREEN, 2003, p. 31). Os homossexuais também se constituíam como novos sujeitos nas lutas sociais, seja na luta pela despatologização da homossexualidade, no combate a AIDS, na organização de novos grupos ou no enfrentamento à violência e à discriminação.

A "saída do gueto", como propunha o Lampião da Esquina, foi pela organização do movimento homossexual ${ }^{13}$. Desse modo, o Lampião passou a ser um dos principais veículos de politização da homossexualidade. Assim, foi criado em 1978, o Núcleo de Ação pelos Direitos dos Homossexuais, sendo rebatizado, posteriormente, com o nome de Somos - Grupo de

\footnotetext{
13 Entretanto, "artistas brasileiros como Caetano Veloso, o Grupo Secos \& Molhados, com seu vocalista Ney Matogrosso, e o grupo teatral Dzi Croquettes, liderado pelo coreógrafo Lennie Dale", entre outros (SIMÕES; FACCHINI, 2009, p. 75). Embora não estivessem envolvidos diretamente no movimento organizado, contribuíram para visibilidade ao homoerotismo, pois, com suas performances e com seu "desbunde", questionavam os valores morais e a repressão da época, já que o país vivia uma ditadura militar (FRY; MACRAE, 1984).
} 
Afirmação Homossexual, em homenagem a uma publicação da Frente de Libertação Homossexual da Argentina (GREEN, 2000; OKITA, 2007; SIMÕES e FACCHINI, 2009).

Segundo Simões e Facchini (2009),

\begin{abstract}
O grupo, naquele momento, era composto por cerca de quinze homens, que passaram a realizar reuniões semanais dedicadas a relatos confessionais, seguindo uma prática já consagrada nos grupos feministas e também a discussões sobre a possibilidade de formação de um movimento político mais amplo em aliança com feministas e outras minorias. (SIMÕES; FACCHINI, 2009, p. 96).
\end{abstract}

O início do Somos é marcado pela sua formação mista, tendo gays e lésbicas atuando juntos, porém, as mulheres passaram a ser organizar em um subgrupo, pois identificaram práticas machistas entre os homossexuais masculinos, dessa forma criaram o Grupo LésbicoFeminista, já que "a discussão surgida em torno da questão do machismo levou as lésbicas a organizarem-se como uma semi-autonomia dentro do grupo, para poderem colocar as suas questões específicas.” (OKITA, 2007, p. 91). Possivelmente, vêm daí as cisões e as disputas que existem no seio do Movimento LGBT até dos dias atuais que ocasionaram as inúmeras transformações na sigla e nas lutas do segmento.

$\mathrm{Na}$ década de 1980, foi iniciada com o processo de abertura política (1985) e redemocratização (1988), criando uma possibilidade de expressividade dos novos movimentos sociais, conforme enaltece Gohn (1997, p. 269), com “características da natureza humana, especificamente sexo, idade, raça e cor", denominados como movimento de mulheres, movimento negro, movimento homossexual, entre outros.

Nesse período, surgiram inúmeros grupos homossexuais, em São Paulo, que se espalharam pelo país e, em 1980, tiveram a coragem de realizar o I Encontro Brasileiro de Homossexuais (EBHO) ${ }^{14}$ simultaneamente com o I Encontro de Grupos Homossexuais Organizados (EGHO). O evento aconteceu em plena Semana Santa, de 04 a 06 de abril daquele ano (ESTRUTURAÇÃO, 2005).

Simões e Facchini (2009, p. 106) relatam que

Cerca de duzentas pessoas compareceram à parte fechada do encontro, o I Egho, integrantes e convidados dos grupos Somos-SP, Eros-SP, Libertos/Guarulhos-SP,

\footnotetext{
${ }^{14} \mathrm{O}$ EBHO se tornou um evento de referência da militância LGBT, ficando com essa nomenclatura até o V EBHO que ocorreu em Recife-PE, em 1991. Porém, ao longo dos anos, passou por diversas denominações, sendo a primeira, em 1993, quando da realização do VI Encontro Brasileiro de Lésbicas e Homossexuais (EBLHO), já em 1995, se tornou o Encontro Brasileiro de Gays e Lésbicas (EBGL). Após inúmeras discordâncias, a partir de 1997, o IX Encontro incorpora as Travestis e vira o EBGLT. O Encontro teve 13 edições, e, no $13^{\circ}$ EB LGBT - Encontro Brasileiro de Lésbicas, Gays, Bissexuais, Travestis e Transexuais, que aconteceu em Porto Alegre, passou a adotar o uso da sigla LGBT (ESTRUTURAÇÃO, 2005).
}

\# Tear: Revista de Educação Ciência e Tecnologia, Canoas, v.8, n.1, 2019. 
Somos/Sorocaba-SP, Somos-RJ, Auê-RJ, Beijo Livre/Brasília-DF, além de representantes de Belo Horizonte, Vitória, Goiânia, Curitiba [...]. Recheado de discussões longas e acirradas, o encontro evidenciou que entre os integrantes dos diversos grupos representados havia vários simpatizantes de partidos políticos de esquerda, legais, como o recém-criado Partido dos Trabalhadores (PT), ou clandestino em via de legalização, como o PCB e o Partido Comunista do Brasil (PC do B), além da Convergência Socialista, que naquele momento aderira ao PT.

Dessa forma, percebemos que o movimento LGBT, desde seu início, dialogava com as questões políticas existentes no Brasil, tanto que Green (2003) e Okita (2007) corroboram esta informação, afirmando que os gays e as lésbicas estiveram presentes nas lutas pelas liberdades políticas e nas lutas pelos direitos econômicos, sociais e culturais, quando diferentes segmentos resolvem construir e fundar um partido de esquerda, a exemplo do Partido dos Trabalhadores (PT), de modo que participaram das lutas gerais no processo da transição política a partir de 1974 nas lutas pela Anistia e por direitos sociais, como na caminhada do dia $1^{\circ}$ de maio de 1980, na greve do ABC.

De acordo com Green (2003), os partidos políticos de esquerda passaram muito tempo para integrar as bandeiras do movimento LGBT nos seus programas políticos, tanto no Brasil como na América Latina, alegando, como justificativa, que a prioridade deveria ser as alianças com a classe operária, uma vez que os LGBTs só pautavam a luta identitária.

A segunda fase do movimento acontece a partir de 1980, quando floresceu e se espalhou pelo país afora. É datada, nesse período, a criação do Grupo Gay da Bahia - GGB (1980); do Grupo de Atuação Homossexual de Recife/Olinda - GATHO (1981); Grupo Dialogay, de Sergipe (1981); do Grupo Triângulo Rosa (1985) e do Grupo Atobá (1986), ambos do Rio de Janeiro, entre outros. ${ }^{15}$

Nesse período, duas ações foram significativas para o segmento LGBT: o Grupo Triângulo Rosa, liderado por João Antonio Mascarenhas, e o GGB, liderado por Luiz Mott, fizeram uma intensa campanha para que, em 9 de fevereiro de 1985, o Conselho Federal de Medicina deixasse de considerar a homossexualidade como doença e, assim, transferiu o diagnóstico para outras circunstâncias psicossociais. Segundo Reis (2012, p. 56), “o Brasil antecedeu em cinco anos aprovação em 17 de maio de 1990, pela 43 ${ }^{\text {a }}$ Assembleia Geral da

\footnotetext{
15 Desse período, o único ainda em atuação é o Grupo Gay da Bahia (GG), sendo considerado o mais antigo grupo homossexual em funcionamento na América Latina. Ver http://www.ggb.org.br/cronologia_movimento_homossexual.html. Acessado em: 28 mar. 2019.
} 
Organização Mundial da Saúde (OMS), da retirada do código $302.0^{16}$ da Classificação Internacional de Doenças (CID)".

A outra ação foi à tentativa de "incluir uma expressa proibição de discriminação por 'orientação sexual' na Constituição de 1988” (HOWES, 2003, p. 302). Mas não se obteve êxito, em virtude da oposição dos fundamentalistas religiosos.

Contudo, esse período coincide com a chegada da AIDS, acontecendo, assim, a institucionalização do movimento que passa a firmar parceria com o Estado, realizando iniciativas preventivas junto aos gays, fortalecendo ações e estruturação de grupos organizados.

Conforme ressalta Facchini (2005, p.93),

\begin{abstract}
Antes do final da primeira metade dos anos 1980, houve uma drástica redução na quantidade de grupos presentes no movimento. Isto pode ser justificado, entre outras coisas, pelo surgimento da epidemia da Aids, então chamada "peste gay", e seu poder de desmobilização das propostas de liberação sexual, e, ainda, pelo fato de muitas lideranças terem se voltado para a luta contra a Aids, criando as primeiras respostas da sociedade civil à epidemia.
\end{abstract}

A AIDS, ao mesmo tempo em que fragilizou o segmento, já que muitos homossexuais adoeceram, crescendo o pavor na população, pois a "peste gay" era então associada aos homossexuais, provocou uma renovação na militância LGBT que viu, no financiamento das ações de prevenção às DST/AIDS, uma forma de criação de Organizações Não Governamentais (ONGs), para atuar no combate da AIDS.

Assim, em 1994, o Programa Nacional de DST/AIDS ${ }^{17}$ foi reformulado e passou a descentralizar suas ações de prevenção às DST/AIDS. O movimento, então, tornou-se parceiro do Estado. Desta forma, o movimento LGBT se utilizou do que a autora Maria da Gloria Gohn (1997, p. 107) chama de "oportunidade política" e, assim, utilizou os recursos destinados ao combate da AIDS, para fortalecer a luta pelos direitos humanos dos LGBT.

De acordo com Rossi (2010, p. 82),

Este estreitamento das relações carrega em si uma grande contradição. Por um lado, os recursos e financiamentos fornecidos pelo Ministério da Saúde a grupos homossexuais para a prevenção das DST/AIDS na comunidade homossexual possibilitaram a reestruturação do movimento em todo o país, propiciando um crescimento e fortalecimento do movimento homossexual brasileiro. Por outro, acabou por amenizar as tensões entre essas duas instituições. Do claro papel de

\footnotetext{
16 Definia homossexualidade como desvio e transtorno sexual, utilizando a expressão homossexualismo como doença no CID.

${ }^{17}$ O Programa Nacional de DST e AIDS, hoje o atual Departamento de DST, AIDS e Hepatites Virais, foi criado em 1986, por recomendação do Programa Conjunto das Nações Unidas sobre a AIDS, instância da Organização Mundial da Saúde (OMS).
} 
oponente ao Estado, o movimento passou a ser parceiro dele na luta ao combate a AIDS, subjacente as campanhas de prevenção contra a AIDS, na luta contra o preconceito e pela afirmação dos direitos sexuais de gays, lésbicas, bissexuais, travestis e transgêneros. Essa foi a fórmula que o movimento encontrou para se sustentar e se fortalecer.

O Estado identificou a necessidade de dialogar e de envolver o segmento como principal parceiro, para realizar o papel de prevenção às DST/AIDS, por isso, firmou parcerias com as organizações, subsidiando recursos para o desenvolvimento de projetos, articulando a promoção da saúde com a organização do movimento e o seu engajamento na luta contra a epidemia. A princípio, foi uma iniciativa salutar, mas transformou o movimento social em organizações não-governamentais com cara de empresas a serviço do Estado, necessitando de CNPJ e de contratar profissionais de diversas áreas, para executar a prestação de serviço ao governo.

Ainda segundo Rossi (2010, p. 90),

\begin{abstract}
Além disso, o crescimento do número de ONGs habilitadas para concorrer ao financiamento de projetos aumentou, e os recursos, não. Pelo contrário, na medida em que a política de combate ao HIV ia dando resultados positivos, tais recursos foram ficando mais escassos. Isso provocou uma disputa interna entre as ONGs que pleiteavam verbas junto ao Governo Federal.
\end{abstract}

Nesse ínterim, acontece a terceira fase do Movimento LGBT Brasileiro, com a fundação da Associação Brasileira de Lésbicas, Gays, Bissexuais, Travestis e Transexuais (ABGLT), durante o VIII Encontro Brasileiro de Gays e Lésbicas, realizado de 28 a 31 de janeiro de 1995, em Curitiba/PR. A década de 1990 é marcada pela proliferação de grupos ativistas, formação de redes e eventos específicos, como o Encontro Nacional de Travestis e Transexuais que Atuam na Luta contra a Aids (ENTLAIDS), em 1993, e o I Seminário Nacional de Lésbicas (SENALE), em 1996. Como também a organização e o crescimento do número de paradas LGBT em todo o Brasil.

Júlio Simões e Regina Facchini dizem que

[...] as paradas, como manifestações de visibilidade de massa, marcam a expressão social e política do movimento LGBT dos últimos anos e são, também, um terreno privilegiado para se apreciar o cruzamento das diversas conexões do movimento com o mercado e o Estado. (SIMÕES; FACCHINI, 2009, p. 151).

Concordamos com os autores citados, pois entendemos que as paradas se tornaram o maior evento do segmento e se tornaram, nos últimos anos, um ato político consolidado, fazendo com que, pelo menos uma vez no ano, a sociedade veja lésbicas, gays, bissexuais, 
travestis e transexuais tomando as ruas de dezenas de cidades brasileiras como um direito social. Embora que, para uma parte da população, as paradas sejam vistas de forma carnavalesca, foi com esse formato, cheio de glamour, de irreverência e de descontração que a militância identificou como o destinado a fazer suas reivindicações e suas propostas ao Poder Público e, assim, viver em coletividade.

\section{A resistência do Movimento LGBT da Paraíba}

A efervescência causada pelo surgimento do movimento homossexual na região Sudeste fez com que os homossexuais começassem a se organizar em outras regiões do Brasil. No Nordeste, isso só veio acontecer no ano de 1980, conforme já citado anteriormente, com a criação do Grupo Gay da Bahia e o Dialogay de Sergipe. Esse período foi marcado pelo início do processo de abertura política, já que se almejava o fim do Regime Militar.

[...] O surgimento dos primeiros grupos de militância em vários segmentos, entre eles o homossexual, na década seguinte está vinculado às contínuas mobilizações e erupções de coletivos de civis descontentes com a gestão do Estado, e de modo geral, de grupos e coletividades descontentes com a política [...]. (OLIVEIRA, 2014, p. 10).

Na Paraíba, como nos demais estados, a juventude questionava os valores morais e sexuais da época, em virtude da forte repressão causada pela Ditadura Militar. Com isso, no interior das universidades, começavam a surgir as discussões sobre homossexualidade e, assim, foi criado o primeiro grupo homossexual da Paraíba, o Nós Também. Conforme ressalta Oliveira (2014, p. 12), “o surgimento do grupo ‘Nós Também’ (NT), em 1981 está estritamente vinculado às experiências de jovens universitários e professores da Universidade Federal da Paraíba em grupos de discussão".

O Grupo Nós Também teve uma curta duração, de 1981 a 1983, contando com a participação de professores e alunos da UFPB. Paralelamente, surgiu, fora dos muros da UFPB, no mesmo período, o Grupo Beira da Esquina, que dialogava com o movimento estudantil, com o movimento negro, o movimento de mulheres, o dos artistas e o dos líderes comunitários, além de estudantes e professores da mesma instituição de ensino.

Só na década de 1990, o movimento LGBT ganha força na Paraíba com o surgimento do Movimento do Espírito Lilás (MEL), em 06 de março de 1992. Para Luciano Vieira (2008, p. 157), ${ }^{18}$ a primeira fase do MEL foi "um momento interno de auto reconhecimento como

$18 \mathrm{O}$ professor Luciano Bezerra Vieira foi um dos pioneiros na luta pela cidadania e direitos da população LGBT na Paraíba e dedicou-se durante toda a sua vida ao movimento social. Faleceu em 24 de dezembro de 2017.

\# Tear: Revista de Educação Ciência e Tecnologia, Canoas, v.8, n.1, 2019. 
sujeitos de direitos, para depois, na fase seguinte, conquistar o reconhecimento social." (VIEIRA, L., 2008, p. 157).

Nos primeiros anos, o MEL era um grupo misto, composto por gays, lésbicas e algumas travestis, e tinha uma forte atuação no cenário nacional. Em 1995, esteve presente no processo de fundação da ABGLT; em 1997, foi o primeiro grupo homossexual a filiar ao Movimento Nacional de Direitos Humanos (MNDH) e a participar, efetivamente, da fundação e construção da Central dos Movimentos Populares (CMP). O MEL surgiu na década de 1990, período em que as lutas sociais emergiam, por isso se diferenciava das demais entidades LGBT da época, porque assumia outras bandeiras como a luta pela moradia, a inserção nos direitos humanos, a formação a partir da educação popular e a defesa pela saúde pública, entretanto a plataforma prioritária sempre foi o enfrentamento à homofobia, sendo a primeira entidade a expor publicamente na imprensa paraibana os atos de violência e de criminalidade que acometia o segmento LGBT, mas com forte resistência da mídia conservadora que, na maioria das vezes, fazia chacota da atuação dos militantes.

De acordo com Luciano Vieira (2015, p. 5), a partir de 1995, o MEL “começa a realizar encontros estaduais, seminários, semanas da consciência LGBT em que buscava a participação de representantes de diversos municípios". Dessa forma, começava a se gestar o movimento LGBT da Paraíba que despontou na década de 2000, época em que as lésbicas e as travestis percebem a necessidade de se organizarem em suas entidades, para fortalecer a luta identitária, seguindo, assim, o andamento que acontecia no segmento LGBT em todo o país.

Logo, em 19 de outubro de 2002 foi fundada a Associação das Travestis da Paraíba (ASTRAPA). Fernanda Benvenutty (2008, p. 161), afirma que a criação da ASTRAPA se deu a partir dos anseios das travestis paraibanas que desejavam ter uma entidade que atendesse suas especificidades, já que o MEL tinha um recorte identitário voltados aos homens gays. Em 20 de novembro de 2002, foi fundado o Grupo de Mulheres Maria Quitéria (GMMQ), com a finalidade de ser uma entidade de defesa das mulheres lésbicas e bissexuais.

Ao longo dos anos, o movimento LGBT conquistou alguns avanços em termos de políticas públicas no Brasil, cujo desdobramento só veio acontecer nos anos 2000, com a realização das conferências, elaboração de programas e projetos e financiamento de ações nas três esferas de governo. 


\section{Considerações Finais}

Nos últimos anos, o Movimento LGBT tem conquistado no contexto democrático alguns avanços no campo da cidadania. De forma mais detalhada, podemos destacar: na dimensão política, a participação social com a realização de conferências de políticas públicas para LGBT, conselhos e gestão de políticas pública; na dimensão civil, o movimento tem demandado e conquistado, junto ao poder público, a criação de centros de referência de combate à homofobia, embora a violência ainda persista e constitua a mais grave violação de direitos.

Por outro lado, os avanços no uso do nome social das travestis e transexuais nas repartições públicas e a implantação do Processo Transexualizador no Sistema Único de Saúde (SUS) demonstram o quanto, no que diz respeito à cidadania civil, os LGBTs têm conquistado em termos de direitos; na dimensão econômica e cidadã, os LGBTs têm galgado reconhecimento na inclusão dos casais homoafetivos no Imposto de Renda conjunto, assim como o reconhecimento do poder judiciário de união estável para recebimento de benefícios previdenciários junto ao INSS; já no aspecto social, a conquista de direitos tem ocorrido na inclusão de companheiro (a) do mesmo sexo como beneficiário (a) de plano de saúde e o reconhecimento da união homoafetiva como entidade familiar pelo Supremo Tribunal Federal.

Ao mesmo tempo em que temos avanços relacionados à cidadania LGBT nas dimensões civil, econômica e social, anteriormente listadas, existem tensões atuais, no âmbito do parlamento, distintamente com o poder judiciário e executivo, o que tem dificultado a conquista de uma legislação que criminalize a homofobia no Brasil. Mesmo assim, do ponto de vista político, o movimento LGBT continua em outros canais de participação, seja na gestão de políticas públicas, nas esferas públicas da cidadania, nos comitês, ou nos conselhos de direitos e de políticas públicas.

As conquistas do movimento LGBT foram influenciadas pela ousadia daqueles(as) que lutaram contra a discriminação desde a Revolta de Stonewall, fato que acabou entusiasmando outros ativistas em todo mundo, inclusive, no Brasil dos anos de 1970, período em que assumir uma posição política significava perder a liberdade e, às vezes, a própria vida.

Por isso, a criação do Jornal Lampião da Esquina, no Rio de Janeiro e a fundação do Grupo Somos, em São Paulo, são fatos emblemáticos, já que representam o pontapé inicial para a luta dos que ousaram assumir uma orientação sexual diferente da hegemônica e imposta pela sociedade, em um momento que o país fazia a transição do regime autoritário para o democrático, possibilitando a criação do movimento LGBT que foi formando em várias regiões do país, inclusive no Estado da Paraíba. 


\title{
THE TRAJECTORY OF SOCIAL MOVEMENT FOR THE RECOGNITION OF LGBT CITIZENSHIP
}

\begin{abstract}
This paper summarizes one of the themes addressed in a master's research thesis, which sought to analyze the actions implemented by the Brazilian Program without Homophobia of the Federal Government, from its transversality with public policies and interfaces with the movement for Lesbian, Gay, Bisexual, Transgender and Transgender (LGBT) at A local level. In this way, the objective of this article is to reflect the notion of citizenship, starting from the history of the LGBT social movement, using the following theoretical references: Marshall (1976); Dagnino (1994); Benevides (1996); Cortina (2005); Gohn (1997). It is, therefore, a bibliographical research, in which an exploratory literature review was carried out based on a qualitative approach, where we highlight the trajectory of the LGBT Movement, contemplating international, national and local levels, emphasizing its emergence and its struggle for the recognition of the citizenship of LGBT, from scientific works and writings of their own militancy, such as Green (2003); Facchini (2005); MacRae (2011); Reis (2012); Vieira, L. (2015). As a result, we point out the achievements of the LGBT movement in the democratic context from the political, civil, economic and social dimensions as part of the trajectory and recognition of the social struggle and LGBT citizenship.
\end{abstract}

Keywords: Social movement. Citizenship. History of the LGBT Movement.

\section{Referências}

ABGLT - Associação Brasileira de Lésbicas, Gays, Bissexuais, Travestis e Transexuais. Manual de Comunicação LGBT: Lésbicas, Gays, Bissexuais, Travestis e Transexuais. Curitiba: ABGLT, 2010.

BENEVIDES, Maria Victoria de Mesquita. Educação, democracia e direitos humanos. In: Jornal da Rede Brasileira de Educação em Direitos Humanos. São Paulo: RBEDH, 1997. Disponível em: <http://www.dhnet.org.br/educar/redeedh/bib/benevid.htm>. Acessado em: 19 mai. 2019.

BENEVIDES, M. V.de M. A Cidadania Ativa: referendo, plebiscito e iniciativa popular. São Paulo: Ática, 1996.

BENVENUTTY, Fernanda. Associação das Travestis da Paraíba - ASTRAPA. In: GENTLE, Ivanilda Matias; ZENAIDE, Maria de Nazaré Tavares; GUIMARÃES, Valéria Maria Gomes. Gênero, diversidade sexual e educação: conceituação e práticas de direito e políticas públicas. João Pessoa: Universitária da UFPB, 2008. p. 161-163.

BERUTTI, E. B. Gays, Lésbicas, Transgenders: o caminho do arco-íris na cultura norteamericana. Rio de Janeiro: EdUERJ, 2010.

CORTINA, A. Cidadãos do mundo: para uma teoria da cidadania. Trad. de Silvana Cobucci Leite. São Paulo: Loyola, 2005. 
DAGNINO, Evelina. Os movimentos sociais e a emergência de uma nova noção de cidadania. In: DAGNINO, Evelina (Org.). Os anos 90: política e sociedade no Brasil. São Paulo: Brasiliense, 1994. p. 103-115.

ESTRUTURAÇÃO - GRUPO LGBT DE BRASÍLIA. Revista Memória Encontro Brasileira de Gays, Lésbicas e Transgêneros. Brasília: Estruturação, 2005.

FACCHINI, R. Sopa de Letrinhas: movimento homossexual e produção de identidades coletivas nos anos 1990. Rio de Janeiro: Garamond, 2005.

FRY, Peter. Apresentação. In: SIMÕES, Júlio Assis; FACCHINI, Regina. Do movimento homossexual ao LGBT. São Paulo: Fundação Perseu Abramo, 2009.

FRY, P.; MACRAE, E. O que é homossexualidade. São Paulo: Brasiliense, 1984.

GOHN, M. da G. Movimentos sociais na contemporaneidade. Revista Brasileira de Educação. Rio de Janeiro, v. 16, n. 47, p. 333-362, 2011.

GOHN, M. da G. 500 anos de lutas sociais no Brasil. Movimentos sociais, Ongs e Terceiro Setor. Revista Mediações. Londrina, v. 5, n.1, p. 11-40, 2000.

GOHN, M. da G. Teoria dos Movimentos Sociais: paradigmas clássicos e contemporâneos. 6 ed. São Paulo: Loyla, 1997.

GOMES, J. C. Direitos Humanos, Educação e Cidadania LGBT: Análise das Ações do Programa Brasil Sem Homofobia em João Pessoa/PB. 2016. 145 f. Dissertação (Mestrado em Educação) - Programa de Pós-Graduação em Educação da Universidade Federal da Paraíba, João Pessoa, 2016.

GREEN, J. N. Além do Carnaval: a homossexualidade masculina no Brasil do século XX. São Paulo: UNESP, 2000.

GREEN, J. N.. A Luta pela Igualdade: desejos, homossexualidade e a esquerda na América Latina. Cadernos AEL: homossexualidade, sociedade, movimento e lutas, Campinas, Unicamp/IFCH/AEL, v. 10, n 18/19, p. 13-44, 2003.

HOWES, R. João Antônio Mascarenhas (1927-1998): pioneiro do ativismo homossexual no Brasil. Cadernos AEL: homossexualidade, sociedade, movimento e lutas, Campinas, Unicamp/IFCH/AEL, v. 10, n 18/19, p. 287-314, 2003.

MACRAE, E. Os respeitáveis militantes e as bichas loucas. In: COLLING, Leandro (Org.). Stonewall 40 + o que no Brasil? Salvador: EDUFBA, 2011. p. 21-36.

MARCONI, M. de A.; LAKATOS, E. M. Técnicas de Pesquisa: planejamento e execução de pesquisa, amostragens e técnicas de pesquisa, elaboração, análise e interpretação de dados. 7 ed. São Paulo: Atlas, 2011.

MARSHALL, T. H.. Cidadania, classe social e status. Rio de Janeiro: Zahar, 1976. 
MARSIAJ, J. P. P. Gays ricos e bicas pobres: desenvolvimento, desigualdade socioeconômica e homossexualidade. Cadernos AEL: homossexualidade, sociedade, movimento e lutas, Campinas, Unicamp/IFCH/AEL, v. 10, nº18/19, p. 129-145, 2003.

OKITA, H. Homossexualidade: da opressão à libertação. São Paulo: Sundermann, 2007.

OLIVEIRA, Thiago de Lima. Levantar Bandeira e Dar Pinta: elementos para uma historiografia do movimento LGBTT na Paraíba. João Pessoa, 2014.

REIS, A. L. M. dos. Avanços e Desafios para os Direitos Humanos das Pessoas LGBT. In: VIEIRA, Tereza Rodrigues (Org.). Minorias Sexuais: direitos e preconceitos. Brasília: Consulex, 2012. p. 55-68.

ROSSI, A. J. Avanços e Limites da Política de combate à Homofobia: uma análise do processo de implementação das ações para a educação do Programa Brasil sem Homofobia. 2010. 185 f. Dissertação (Mestrado em Educação) - Universidade Federal do Rio Grande do Sul, Porto Alegre, 2010.

SIMÕES, J. A.; FACCHINI, R. Do movimento homossexual ao LGBT. São Paulo: Fundação Perseu Abramo, 2009.

VIEIRA, Luciano Bezerra. Movimento do Espírito Lilás - Mel (1992 - 2015): um breve histórico. João Pessoa, 2015.

VIEIRA, F. D. Onde estavam as travestis durante a Ditadura? Blog balaio de gatos doidos de pedras. [S. l.], 06 abr. 2015. Disponível em:

<>http://maristelafarias6.blogspot.com/2015/04/onde-estavam-os-travestis-durante.html. Acesso em: 20 mar. 2019. 